\title{
Impairments of Social Interaction in Depressive Disorder
}

\author{
Erhan Akinci, Max-Oskar Wieser, Simon Vanscheidt, Shirin Diop, Vera Flasbeck, \\ Burhan Akinci, Cora Stiller, Georg Juckel ${ }^{\bowtie}$, and Paraskevi Mavrogiorgou \\ Department of Psychiatry, Ruhr-University Bochum, LWL-University Hospital, Bochum, Germany
}

Objective Despite the numerous findings on the altered emotion recognition and dysfunctional social interaction behavior of depressive patients, a lot of the relationships are not clearly clarified.

Methods In this pilot study, 20 depressive patients (mean \pm SD, 38.4 \pm 14.2 ) and 20 healthy subjects (mean \pm SD, 38.9 \pm 15.3 ) (each in dyads) were videographed. We then analyzed their social interaction behavior and emotion processing in terms of emotion recognition, their own emotional experience, and the expression of emotions under the conditions of a semi-structured experimental paradigm.

Results Patients showed more significant impairment regarding the dimensions of social interaction behavior (i.e., attention, interest, and activity) and their interaction behavior was characterized by neutral affectivity, silence, and avoidance of direct eye contact. This interactive behavioral style was statistically related to depressive psychopathology. There were no differences concerning emotion recognition.

Conclusion Impairments of non-verbal and verbal social interaction behavior of depressive patients seem to be less associated with disturbances of basic skills of emotion recognition.

Psychiatry Investig 2022;19(3):178-189

Keywords Depressive disorder; Emotion recognition; Expression of emotions; Video-based behavioral analysis; Social interaction.

\section{INTRODUCTION}

In clinical-psychiatric practice, the analysis and evaluation of a patient's facial expressions play a crucial role in diagnostics and during the overall therapy progress. A clinical diagnosis can only be made on basis of a subjective, impressionrelated assessment of the patient's expression and interaction behavior. Furthermore, the evaluation of the therapy process depends on the patient's mimic feedback to the therapist. Although numerous studies have investigated the dimensions of emotion processing, such as emotion recognition, the perception of one's own emotionality and the expression of emotions, their results can be seen as inconsistent. ${ }^{1-5}$ Studies on emotion recognition on basis of the research of Ekman et al. ${ }^{6.7}$ are considered to be the central literature on the relationship between emotion processing and mental disorders. ${ }^{3,5}$ The question of whether the external expression of affect (facial expression)

Received: September 5, 2021 Revised: October 10, 2021

Accepted: November 7, 2021

$\triangle$ Correspondence: Georg Juckel, MD, PhD

Department of Psychiatry, Ruhr-University Bochum, LWL-University Hospital, Alexandrinenstr.1, 44791 Bochum, Germany

Tel: +49-234-5077-1100, Fax: +49-234-5077-1119, E-mail: georg.juckel@rub.de

(c) This is an Open Access article distributed under the terms of the Creative Commons Attribution Non-Commercial License (https://creativecommons.org/licenses/by$\mathrm{nc} / 4.0$ ) which permits unrestricted non-commercial use, distribution, and reproduction in any medium, provided the original work is properly cited. represents the internal emotional state (emotion) has also been investigated sufficiently. For instance, Juckel et al. ${ }^{8-12}$ conducted a kinematic facial expression analysis by examining different groups of psychiatric patients with a motion detector and found differences in their facial expressions. Within the framework of an emotional induction experiment using "Mr. Bean" sketches, the kinematic detailed analysis of the laughing movement of depressive patients revealed significantly lower speed measures when compared to healthy study participants. In particular, patients with severe depressive symptoms showed the slowest initial speeds in the laughter movements. ${ }^{13-15} \mathrm{In}$ terestingly, the depressive patients also showed slower initial speeds than the healthy subjects. Hypomimia (reduced facial expressions) is considered to be the main characteristic of depressed patients and is discussed as essential for a deficit interactive dynamic. ${ }^{5}$ However, the impairments of social interaction skills in depressive patients are diverse. A review by Kupferberg et al. ${ }^{15}$ showed that these deficits of social interaction skills manifest themselves in reduced motivation to communicate, lack of cooperativeness, and ultimately dysfunctional interaction behavior. Depression-related alterations in the perception of emotions and emotion processing, as well as cognitive and metacognitive processes have been discussed as being responsible for this. ${ }^{16-18}$ 
Dysfunctional interactions can have a negative vicious circle effect on specific mental disorders. Current studies have shown that depressed patients are particularly sensitive to social rejection stimuli as result of the cyberball paradigm, in which online computer players can exclude each other from participating in a virtual ball game..$^{19}$ As consequence of this hypersensitivity and the perceived social rejection, anxiety and sadness occur more frequently and for longer periods of time, together with increased stress, which is attended by measurable neurobiological-hormonal and immunocytochemical changes. This symptom finally contributes to the negative attribution of social contacts. ${ }^{19-22}$ However, despite the numerous findings on the altered emotion processing and dysfunctional interaction behavior of depressed patients, many connections between these two multidimensional and complex areas have not been clarified. According to Wolf et al., ${ }^{5}$ an important factor seems to be the isolated consideration of individual dimensions of emotion and interaction processes. Additionally, the complexity of physical-motoric and emotional interaction performances within human interaction processes can only be assessed to a limited extent using simple methodological measurements. Innovations in media technology could be used to provide more specific instruments for measuring complex emotional-mimic expressions during an interaction to achieve more valid results. Software-supported behavioral observation (INTERACT) ${ }^{23}$ is a well-proven method and it is frequently used in research on mother-child interaction. Furthermore, important findings regarding the early disturbance of mother-child interaction in the context of postpartum depression have been gained by using video-based behavioral observation software and multimodal data analysis. This ultimately led to the development and establishment of effective therapeutic interventions. ${ }^{24-28}$

Therefore, the aim of our pilot study was to examine depressed patients in regard to emotional experience, mimic expression, and interaction behavior. The experiment was done in pairs of patients and of controls each, so that the healthy person could not dominate the depressed one. In addition, biographical, psychometric and personality traits were assessed as possible influencing factors. In accordance with our hypothesis, we assumed that the severity of depressive symptoms in the patient group was related to deficits in the processing of emotions and in their interactional behavior. The novelty of the INTERACT method is the full and complete digitalized approach so that all actions and reaction of volunteers in the experiment could be analyzed in great detail and e.g. ultradynamics in facial expressions or interactive behavior could be brought to the light of statistical calculations.

\section{METHODS}

\section{Subjects}

In total, 20 patients (mean age 38.4 [SD=14.2]) with a depressive disorder according to ICD-10 and 20 healthy subjects matched by age and sex (mean age 38.9 [SD=15.3]) were examined in this pilot study. Their sociodemographic and clinical characteristics are presented in Table 1.

Male and female healthy subjects without psychiatric or serious somatic illness and without positive family history of mental illness were recruited for the healthy control sample. The further inclusion criteria were a verbal IQ $>70$, sufficient German language skills, and an ability to participate in and to consent for the study according to Helsinki and ICH-GCP requirements. The exclusion criteria of the study were severe somatic diseases or mental illnesses (including organ-brain related mental illnesses, and ethanol or drug addiction), acute suicidal or extraneous endangering behavior, and lack of consent to participate in the study. A detailed anamnesis was taken from all depressive patients and healthy volunteers in a semi-structured interview (duration 45-60 minutes). The psychometric characteristics was gathered using various questionnaires. In addition, a PC-based emotion recognition task was used, which was based on a semi-structured paradigm. In accordance with the participants, a sequence of interaction behavior was recorded.

\section{Measuring instruments}

To measure the general severity of the patients' mental illness, the Clinical Impression Score (CGI) ${ }^{29}$ was used. The Personal and Social Performance Scale (PSP) is a valid, reliable, and standardized instrument for measuring the psychosocial functional level. ${ }^{30,31}$ To evaluate the scale, a PSP total value is determined; for example, the range 71-100 reflects "no or only slight difficulties." The Beck Depression Inventory (BDI-II) ${ }^{32,33}$ and the Hamilton Depression Scale (HAM-D) ${ }^{34}$ were used to assess depressive symptomology. The State-Trait Anxiety Inventory (STAI-I/II) ${ }^{35,36}$ was used to assess the severity of trait and state anxiety. The NEO-FFI according to Costa and McCrae (1989, German translation by Borkenau and Ostendorf 1993, revised 2008 $)^{37}$ was used to measure the following five different personality traits: neuroticism, extraversion, openness to experience, agreeableness, and conscientiousness.

Possible impairments of emotion processing were measured using the Alexithymia-Toronto Scale (TAS-20), ${ }^{38-40}$ which measures difficulties in identifying (TAS-1) and describing (TAS2) feelings, and also externally oriented thinking (TAS-3). The German version of the empathy inventory (IRI) ${ }^{41}$ is the Saarbrücken Personality Questionnaire (SPF), ${ }^{42}$ which was used to investigate empathy and its four dimensions (i.e., perspec- 
Table 1. Sociodemographic and clinical characteristics

\begin{tabular}{|c|c|c|c|}
\hline Variables & Patients $(\mathrm{N}=20)$ & Control $(\mathrm{N}=20)$ & $\mathrm{Chi}^{2}$ or t-test, respectively \\
\hline Age & $38.4 \pm 14.2$ & $38.9 \pm 15.3$ & n.s. \\
\hline \multicolumn{4}{|l|}{ Sex } \\
\hline Women & $11(55)$ & $11(55)$ & n.s. \\
\hline Men & $9(45)$ & $9(45)$ & n.s. \\
\hline \multicolumn{4}{|l|}{ Marital status } \\
\hline Married & $7(35)$ & $8(40)$ & n.s. \\
\hline Divorced/widowed but in a new relationship & $1(5)$ & $2(10)$ & n.s. \\
\hline Single & $12(60)$ & $10(50)$ & n.s. \\
\hline Current relationship & $5(25)$ & $15(75)$ & \multirow{2}{*}{$\chi_{(1)}^{2}=10.00, p=0.002$} \\
\hline No current relationship & $15(75)$ & $5(35)$ & \\
\hline \multicolumn{4}{|l|}{ Educational background } \\
\hline Upper grade & $13(65)$ & $15(75)$ & n.s. \\
\hline Middle grade & $5(25)$ & $5(25)$ & n.s. \\
\hline Low grade & $1(5)$ & 0 & n.s. \\
\hline No school-leaving certificate & $1(5)$ & 0 & n.s. \\
\hline \multicolumn{4}{|l|}{ Occupational status } \\
\hline Currently employed including studies & $7(35)$ & $16(80)$ & \multirow{2}{*}{$\chi_{(1)}^{2}=8.29, p=0.004$} \\
\hline No current active employment & $13(65)$ & $4(20)$ & \\
\hline MWTB-IQ & $104.9 \pm 12.7$ & $111.0 \pm 10.2$ & n.s. \\
\hline PSP & $49.3 \pm 14.7$ & $97.4 \pm 5.5$ & $\mathrm{p} \leq 0.001$ \\
\hline BDI & $24.3 \pm 11.3$ & $1.4 \pm 2.3$ & $\mathrm{p} \leq 0.001$ \\
\hline HAM-D & $23.6 \pm 7.3$ & $0.8 \pm 1.2$ & $\mathrm{p} \leq 0.001$ \\
\hline STAI-I & $53.3 \pm 14.4$ & $30.9 \pm 5.4$ & $\mathrm{p} \leq 0.001$ \\
\hline STAI-II & $57.4 \pm 14.4$ & $30.8 \pm 7.0$ & $\mathrm{p} \leq 0.001$ \\
\hline
\end{tabular}

Data are presented as mean \pm standard deviation or N (\%). PSP, Personal and Social Performance Scale; BDI, Beck-Depressions-Inventory; HAM-D, Hamilton-Depression Scale; STAI, stait und trait fear-inventar; MWST, Wechsler-Mehrfachwortschatztest (=multiple-choice vocabulary intelligence test); n.s., not significant

tive adoption [PT], fantasy [FS], empathic concern [EC] and personal distress $[\mathrm{PD}])$ as an expression of an emotion regulation disorder. According to Paulus, ${ }^{43}$ an overall score (empathy score) can be calculated from the summation of the dimensions PT, EC, and FS as an expression of general empathy.

Finally, the German version of the Positive and Negative Affect Schedule (PANAS) $)^{44}$ was used to assess positive and negative affectivity as an expression of the current emotional state. The multiple-choice vocabulary intelligence test (Mehrfach-Wortschatztest=MWT-B $)^{45}$ was used to determine verbal intelligence.

\section{PC-based emotion recognition task (ERT)}

In order to study the ability to emotion recognition in relation to interactive behavior, such a test was performed on a PC using the Presentation ${ }^{\circledR}$ software (version 17.2, Neurobehavioural Systems Inc., Albany, CA, USA). For this purpose, the participants were instructed to sit on a chair in front of a monitor at distance of approximately $60 \mathrm{~cm}$. At the beginning of the test, a short briefing and an introduction at the PC took place. Afterwards, the participant first completed a test run and was able to familiarize themselves with the system and the procedures. The initial test procedure could then begin: a total of 60 facial expressions were presented for the six basic emotions as defined by Ekman and Friesen (anger, disgust, joy, sadness, fear, and surprise; 10 each $)^{46}$ and $10 \mathrm{im}$ ages with a neutral facial expression were shown for $500 \mathrm{~ms}$ each. Half of the photos showed female persons and the other half male adult persons from the NimStim Set of Facial Expressions (http://www.macbrain.org/resources.htm).

After an inter-stimulus interval of 1,000 ms (white fixation cross on black background), the possible responses (Figure 1) were displayed for 8 seconds. During these 8 seconds, the subject had time to enter their response using the number pad on a conventional keyboard. The numbers on the number pad were labelled with the initial letters of the emotions. The num- 


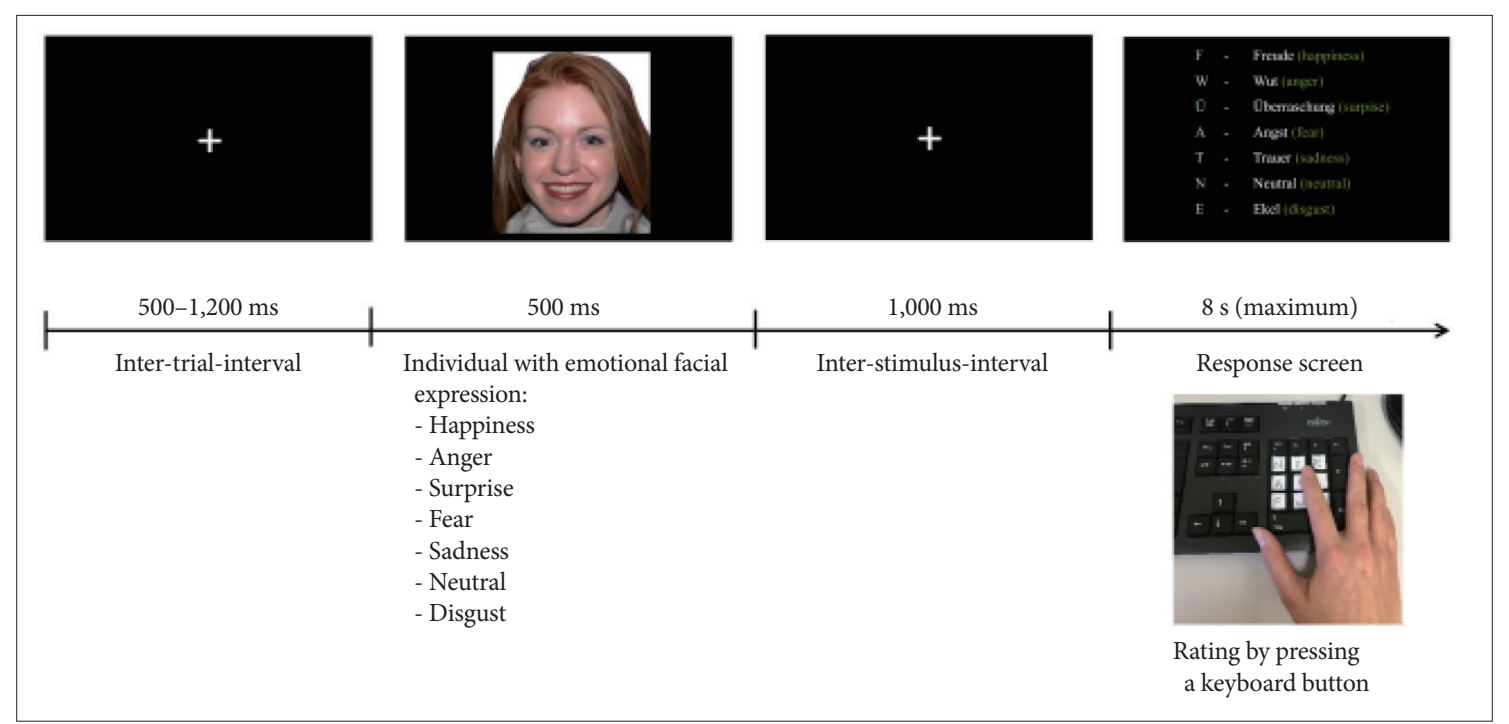

Figure 1. Emotion recognition.

ber 5 in the middle of the pad was marked with a cross, as this was the starting point for the respondent's input finger. If the input was made before or after the 8 seconds, then the answer was evaluated but the reaction time was not recorded. After 8 seconds or after the input, the next trial started after an inter-trial interval of 500-1,200 ms. After approximately $10 \mathrm{~min}$ utes and a total of 70 trials, the test was completed, and the subjects were asked to submit an evaluation of the test. The participants were able to rate the perceived difficulty of the test on a scale of 1 (not difficult at all) to 10 (very difficult). For further data evaluation, the number of correctly recognized emotion expressions and the corresponding reaction time were used.

\section{Videography and interaction analysis (INTERACT; BOEVIAS)}

Two patients and two healthy subjects respectively were videographed in pairs frontally, while a movie with partly humorous but also sad content is shown first (scenes from the Charlie Chaplin film “The Kid," 1921). Watching this movie, participants were recorded with three cameras, which are installed in the videography laboratory (Figure 2) at the Research Department for Experimental Psychopathology of the LWL-University Hospital Bochum. While the participants were watching the movie, their spontaneous emotional-mimic reactions were filmed using iMotions program Affectiva/AFFDEX (I-MOTION GmbH Inc., Koblenz, Germany). Following the 5-minute movie, the participants were asked to stay in the room without receiving concrete instructions about how to behave. The participant's spontaneous behavioral reactions during this time such as in a "couch situation" with non-instructured open possibilities were recorded using video-supported

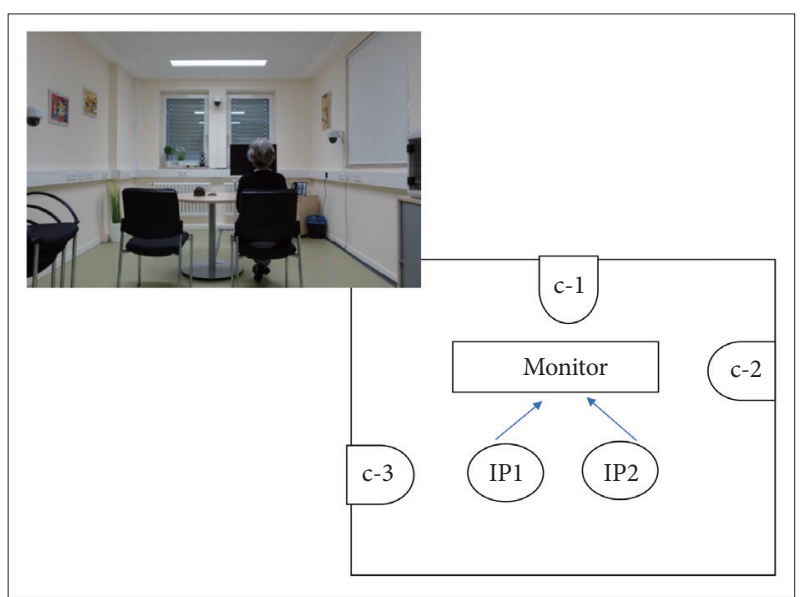

Figure 2. Video-lab and admission modalities. C, camera; IP, interaction partner.

behavioral observation. In a further article, data concerning watching the Charlie Chaplin movie will be presented. Here, we focus on the interactive part of the experiment.

The recordings were then evaluated by two blinded raters (EA/MW) using the Bochum Adult Video-based Interaction Analysis Scale (BOEVIAS). In addition, the BOEVIAS was later repeated by an experienced rater (PM). The BOEVIAS is an evaluation sheet that was developed especially for this study to assess the dimensions of expression level (three items, such as relaxed or neutral expression), relationship level (three items, such as posture or verbal contact), control level (three items, such as attention or activity) and synchronicity (three items, such as verbal or non-verbal synchronicity). Each item of the scales can be rated with 1 (not present) to 5 (distinctly positive). These scales are unipolar in the same direction, so that a total value (by summarizing the subscales) can be formed 
individually for each of the two interaction partners (individual interaction profile, IIP; Mxpt:45). To assess the quality of the overall interaction, the dimension "deficits" is used to record difficulties in these dimensions for each of the interaction partners and abstracted from the sum value. The sum values per interaction partner corrected in this way result in the total value as a measure of the quality of the interaction (BOEVIAS-SID), whereby a high value (Mxpt. 90) corresponds to a better-quality interaction.

As a second step the interaction behavior of only the $5 \mathrm{~min}$ utes "couch situation" was evaluated using the Interact software (INTERACT Software Mangold VideoSync. Version17.1, 2018) (Mangold GmbH\&Co Inc., München, Germany). For behavioral patterns such as eye contact, affects, verbalization and vocalization, body language, and synchronicity codes were predetermined before study begin. Using INTERACT software, blinded rater observed the video material and classified each specific behavior and situation by taking these codes. Thus, the video sequences were quantified and subsequently evaluated. This procedure was performed by trained raters in pairs (MW/SD and EA/SV) (duration 1.5 and 3 hours). The interrater-reliabilities were between Cohan's-Kappa $\kappa=0.68-$ 0.93 (healthy subjects) and $\kappa=0.73-0.95$ (depressive patients), which shows good up to very good agreement values. For further statistical analyzes, the interaction coding values of EA/SV were used (values are given in frequency of events, percentage, and duration in seconds).

\section{Statistical analysis}

The IBM SPSS Statistics 26 program (IBM Corp., Armonk, NY, USA) was used for statistical analysis. For correlational analyzes Pearson and Spearman correlation was used. Parametric (MWTB, PSP, BDI, HAMD, STAI-I/II, TAS, PANAS, $\mathrm{NEO}-\mathrm{FFI}$ ) and non-parametric tests (IRI) were used for group comparison. Statistical significance was tested using the chi test, whereby values $\mathrm{p} \leq 0.05$ were considered statistically significant and values $\mathrm{p} \leq 0.01$ were considered statistically highly significant. Due to the character of a pilot study, no correction for multiple comparisons was used.

\section{Statement of ethics}

This study was approved by the Local Ethics Committee (IRB No.:18-6520) of the Medical Faculty of the Ruhr-University Bochum. All participants have given their written informed consent, after the study was explained to them in full. Patients were informed that the results of the study were published in anonymous form. This was not a clinical trail in the narrow sense and was therefore not registered.

\section{RESULTS}

\section{Description of sociodemographic and clinical characteristics}

Table 1 shows sociodemographic and clinical characteristics of the 20 patients ( 11 women and 9 men) and the 20 healthy subjects matched by age and gender.

In 15 patients (75\%) a recurrent depressive disorder (F33.X) was present after ICD-10, while only five of the patients had their first depressive episode (ICD-10: F32.X). In total, 90\% of patients were taking antidepressants. Two patients had no drug treatment at the time of the study.

Only 5 patients received monotherapy (only with a serotonin agonistic antidepressant). Most often, the patients received a combination treatment consisting of an antidepressant (e.g. SSRI) and a second generation antipsychotic.

The mean age at onset of the disease was $30.6(\mathrm{SD}=13.3)$, the mean duration of the disease was 7.9 ( $\mathrm{SD}=9.3)$ years. The patients had severe psychiatric impairments (CGI) and showed severe functional impairments in more than one psychosocial area (PSP). The patients showed significantly elevated values of psychopathological characteristics, as can be seen in Table 1.

The findings on the affectivity/emotionality of depressive patients and healthy subjects are shown in Table 2 . The pa-

Table 2. Personality dimensions and emotion processin

\begin{tabular}{|c|c|c|c|}
\hline Variables & $\begin{array}{l}\text { Patients } \\
(\mathrm{N}=20)\end{array}$ & $\begin{array}{l}\text { Control } \\
(\mathrm{N}=20)\end{array}$ & t-test \\
\hline NEO-FFI-neuroticism & $2.6 \pm 0.7$ & $1.1 \pm 0.6$ & $\mathrm{p} \leq 0.001$ \\
\hline NEO-FFI-extraversion & $1.6 \pm 0.5$ & $2.5 \pm 0.5$ & $\mathrm{p} \leq 0.001$ \\
\hline NEO-FFI-openness & $2.3 \pm 0.6$ & $2.6 \pm 0.4$ & $\mathrm{p}=0.018$ \\
\hline NEO-FFI-compatibility & $2.5 \pm 0.4$ & $2.8 \pm 0.4$ & $\mathrm{p}=0.024$ \\
\hline NEO-FFI-conscientious & $2.2 \pm 0.6$ & $3.0 \pm 0.5$ & $\mathrm{p} \leq 0.001$ \\
\hline TAS-20-recognize & $22.6 \pm 5.7$ & $10.5 \pm 4.9$ & $\mathrm{p} \leq 0.001$ \\
\hline TAS-20-describe & $17.3 \pm 5.0$ & $9.2 \pm 4.4$ & $\mathrm{p} \leq 0.001$ \\
\hline TAS-20-EOD & $21.4 \pm 5.1$ & $18.3 \pm 4.7$ & $\mathrm{p}=0.053$ \\
\hline TAS-total value & $61.2 \pm 11.4$ & $37.9 \pm 12.7$ & $\mathrm{p} \leq 0.001$ \\
\hline IRI-perspektive taking & $16.7 \pm 5.2$ & $20.3 \pm 4.0$ & $\mathrm{p}=0.020^{*}$ \\
\hline IRI-fantasy & $15.5 \pm 6.1$ & $15.5 \pm 4.7$ & n.s. ${ }^{*}$ \\
\hline IRI-empathic concern & $19.5 \pm 5.3$ & $21.3 \pm 2.9$ & n.s. ${ }^{*}$ \\
\hline IRI-personal distress & $18.1 \pm 6.3$ & $8.5 \pm 3.5$ & $\mathrm{p} \leq 0.001^{*}$ \\
\hline IRI-empathie-value & $51.1 \pm 10.6$ & $57.1 \pm 8.3$ & n.s. ${ }^{*}$ \\
\hline PANAS-positiv & $2.3 \pm 0.7$ & $3.6 \pm 0.6$ & $\mathrm{p} \leq 0.001$ \\
\hline PANAS-negativ & $2.6 \pm 0.9$ & $1.4 \pm 0.4$ & $\mathrm{p} \leq 0.001$ \\
\hline
\end{tabular}

Data are presented as mean \pm standard. *Mann-Whitney-U-test because no standard distribution in the IRI-dimensions existed. NEOFFI, neo five factor inventory; EOD, externally oriented thinking style, IRI, Interpersonal Reactivity Index; TAS, Alexithymia-Toronto Scale; PANAS, Positive and Negative Affect Schedule, Mann-Whitney-Utest 
tients showed significantly higher values in alexithymic features (TAS-20 dimensions) and negative affectivity (PANAS) when compared to healthy control subjects.

In regard to the empathy dimensions, there was just one significant difference in personal distress, possibly implying that the patient's increased values expressed an existing impairment of emotion regulation. The NEO-FFI showed a significantly increased neuroticism value for the patients, while in the extraversion they achieved significantly lower values than the healthy subjects (Table2).

\section{Emotion recognition task (ERT)}

The results of the participants emotion recognition performance are presented in Table 3. There were no significant dif-

Table 3. Emotion recognition

\begin{tabular}{|c|c|c|c|}
\hline Emotion & Patients (N=20) & Control $(\mathrm{N}=20)$ & t-test \\
\hline \multicolumn{4}{|l|}{ Anger } \\
\hline PA & 85 & 89.5 & n.s. \\
\hline RT & $1.3 \pm 0.5$ & $1.2 \pm 06$ & n.s. \\
\hline SE & $7.7 \pm 2.3$ & $7.6 \pm 2.4$ & n.s. \\
\hline \multicolumn{4}{|l|}{ Disgust } \\
\hline PA & 73.5 & 79.5 & n.s. \\
\hline RT & $1.3 \pm 0.7$ & $1.2 \pm 0.6$ & n.s. \\
\hline SE & $5.7 \pm 2.2$ & $6.3 \pm 2.2$ & n.s. \\
\hline \multicolumn{4}{|l|}{ Fear } \\
\hline PA & 41.5 & 50 & n.s. \\
\hline RT & $1.8 \pm 0.8$ & $1.9 \pm 0.9$ & n.s. \\
\hline SE & $5.5 \pm 2.5$ & $5.6 \pm 2.1$ & n.s. \\
\hline \multicolumn{4}{|l|}{ Joy } \\
\hline PA & 80 & 88 & n.s. \\
\hline RT & $0.9 \pm 0.5$ & $0.9 \pm 0.5$ & n.s. \\
\hline SE & $8.3 \pm 2.2$ & $8.8 \pm 1.2$ & n.s. \\
\hline \multicolumn{4}{|l|}{ Neutral } \\
\hline PA & 90 & 92 & n.s. \\
\hline RT & $1.0 \pm 0.6$ & $0.8 \pm 0.4$ & n.s. \\
\hline SE & $8.5 \pm 1.6$ & $8.8 \pm 1.6$ & n.s. \\
\hline \multicolumn{4}{|l|}{ Sadness } \\
\hline PA & 49 & 52 & n.s. \\
\hline RT & $1.9 \pm 0.8$ & $1.7 \pm 0.7$ & n.s. \\
\hline SE & $6.1 \pm 2.5$ & $6.0 \pm 2.0$ & n.s. \\
\hline \multicolumn{4}{|l|}{ Surprise } \\
\hline $\mathrm{PA}$ & 75.5 & 87 & $\mathrm{p}=0.085^{*}$ \\
\hline RT & $1.1 \pm 0.5$ & $1.1 \pm 0.6$ & n.s. \\
\hline SE & $6.1 \pm 1.9$ & $7.4 \pm 1.6$ & $\mathrm{p}=0.031$ \\
\hline
\end{tabular}

Data are presented as mean \pm standard deviation or \%. *statistical tendency. PA, percentage of correctly recognized emotions; RT, reaction time in seconds; SE, self-rated difficulty ferences between depressed patients and healthy controls. Both the patients and the healthy controls showed difficulties in recognizing the emotions of fear and sadness. Furthermore, the patients showed a tendency to recognize the emotion surprise the worst. Self-assessment (with the exception of the emotion surprise, where patients had greater difficulty in recognizing it) did not show any significant group differences.

\section{Interaction behavior (INTERACT; BOEVIAS)}

Based on the Interact findings, both groups showed an interaction behavior that was characterized by a predominance of neutral affect, no verbalization (silence), and gaze direction into the room (and not to look to the other person) (Figure 3). Significant differences between the patients and the healthy controls were found, as shown in Table 4. Significant group difference was observed in quality of affect and gaze direction between the two samples. The significantly different duration of affects was important in the sense that the positive effects were not only half as frequent among the depressed patients but also lasted for a shorter time. In regard to neutral affect, which was significantly more predominant among the patients ( $92 \%$ vs. $76 \%$ in the controls), the duration was also significantly longer (280 seconds vs. 231 seconds). Furthermore, depressed patients showed a reduced number of gazes towards the interaction partner, as well as a reduced duration of this event. Furthermore, the patients showed significantly more extended gazes into the room than the healthy controls (Table 4). In summary, patients differed significantly from the healthy subjects in terms of active willingness to interact, which was present in $65 \%$ of the patients and $100 \%$ of the healthy subjects $(\mathrm{p}=0.004)$. With regard to a body language that promotes interaction, only in the patient group with $n=4(20 \%)$ was a rejecting, negative posture found. Two patients showed a positive and 14 patients (70\%) showed a neutral body language. Among the healthy subjects, neutral body language predominated with $75 \%(n=15)$, while five subjects showed a positive posture facing the interaction partner. There were no differences between the two groups with regard to synchronous behavior, which occurred sporadically (two dyads per group).

As can be seen in Table 4, the depressed patients showed more pronounced impairments in the dimensions of attention, interest, and activity (control level), accompanied by a less favorable individual interaction profile (BOEVIAS-IIP) and a less good dyad interaction (BOEVIAS-SID).

\section{Correlational analyses of psychometric and interaction parameters}

Correlation analysis of Interact variables and further biographical and clinical-psychometric scales showed only few significant correlations. "openness to interact" (AI) correlat- 


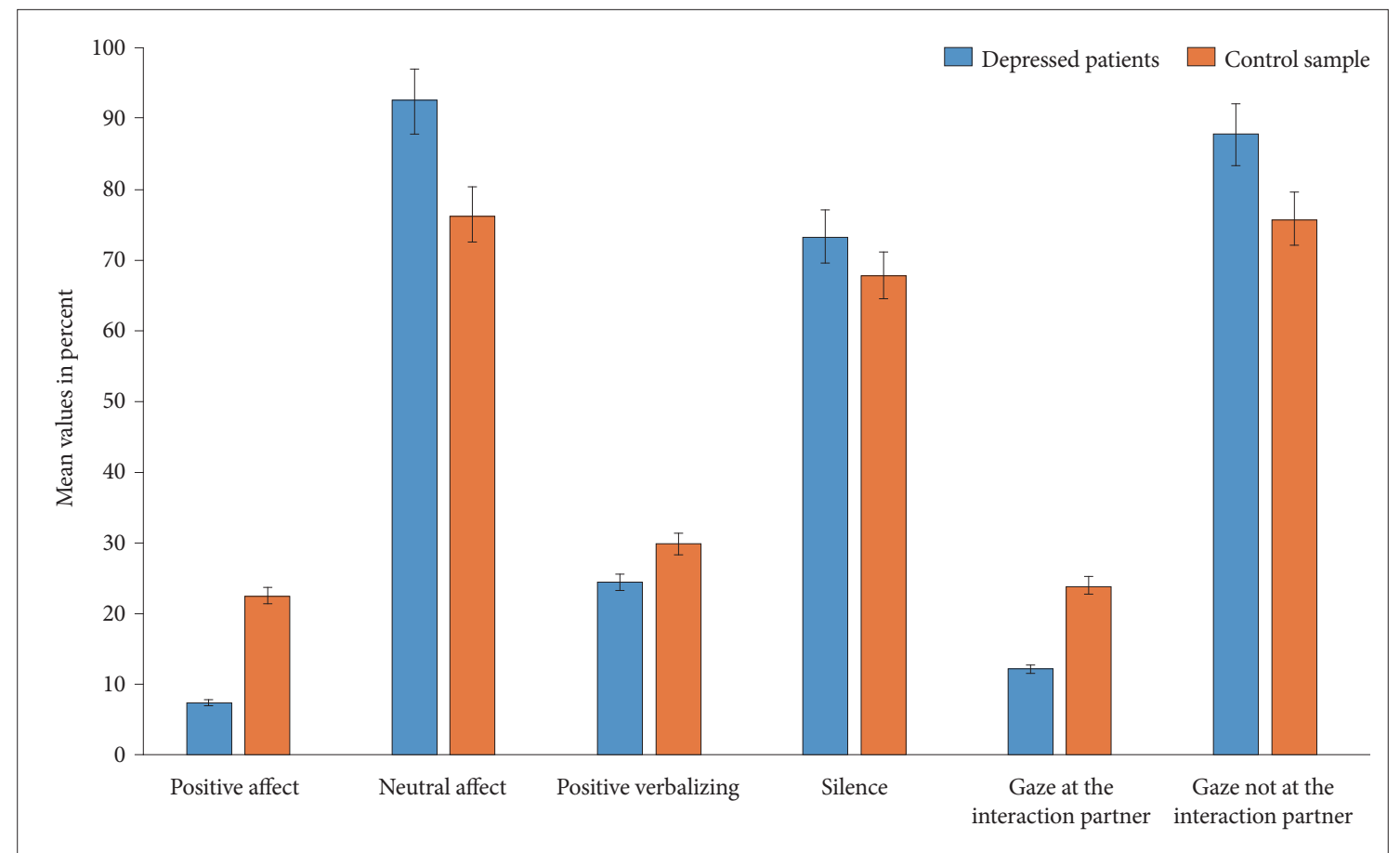

Figure 3. Interact-dimensions (mean values in percent plus/minus standard deviation).

ed inversely with anxiety (STAI-I, $\mathrm{r}=-0.464, \mathrm{p}=0.039$ ) and PANAS was negative $(r=-0.446, p=0.048)$. Positive correlations existed between AI and body language $(r=0.642, \mathrm{p}=0.002)$, the percentage of positive affectivity $(\mathrm{r}=0.587, \mathrm{p}=0.007)$, verbal communication (positive verbalization: $r=0.779, \mathrm{p}<0.001$ or neutral verbalization: $\mathrm{r}=0.678, \mathrm{p}=0.001$ ) and eye contact with the interaction partner $(\mathrm{r}=0.521, \mathrm{p}=0.019)$. In contrast, negative correlations were found between $\mathrm{AI}$ and gaze the other person $(\mathrm{r}=-0.23, \mathrm{p}=0.018)$ or $\mathrm{AI}$ and silence $(\mathrm{r}=-0.785, \mathrm{p}<0.001)$, as well as HAM-D and gaze to the partner $(\mathrm{r}=-0.502, \mathrm{p}=0.024)$. Finally, there was also a correlation between the IRI scale "Empathy-Concern" (EC) and the percentage of positive affects $(\mathrm{r}=-0.460, \mathrm{p}=0.041)$ or neutral affectivity $(\mathrm{r}=0.460, \mathrm{p}=0.041)$.

Significant correlations were found between BOEVIAS-IIP and the severity of depression (BDI; $r=-0.459, \mathrm{p}=0.042$ ), the MWTB-IQ ( $\mathrm{r}=0.520, \mathrm{p}=0.019)$, PANAS positive $(\mathrm{r}=0.561, \mathrm{p}=$ $0.010)$, body language $(r=0.595, p=0.006)$ and active willingness to interact $(\mathrm{r}=0.673, \mathrm{p}=0.001)$.

The influence of medication was tested by means of regression analyzes and only showed a significant relationship to emotion recognition for the dimension fear (beta:-0.343, $\mathrm{p}=0.046$ ). In addition, significant influences were shown for the interaction-dimensions readiness to interact (beta:-0.398, $\mathrm{p}=0.043$ ), percentage of neutral verbalization (beta:-0.493, $\mathrm{p}=0.014$ ), and percentage of silence (beta: $0.455, \mathrm{p}=0.022$ ).

There were no significant correlation coefficients between ERT, INTERACT and BOEVIAS parameters neither in the examined depressed patients or in the healthy volunteers in this experimentally generated interaction situation.

\section{DISCUSSION}

In this pilot study, we used a semi-structured experimental paradigm and semi-quantitative automated analysis methods to investigate the characteristics of emotion processing and interaction behavior in depressed patients compared to healthy subjects. Compared to healthy participants, the patients have a worse socio-economic status, and they suffer more often from psychosocial and psychopathological impairments. The patients significantly show an increased neuroticism; increased alexithymic characteristics; increased negative effects; and negative tension, anger, and fear. ${ }^{44}$

\section{Emotion recognition task (ERT)}

Although the disorders of facial emotion recognition in depressed patients have been investigated in many cases, the findings are inconsistent. Both a global deficit in recognition of different emotions and isolated impairments in the recognition of specific emotions such as joy and sadness are reported. ${ }^{2,47}$ Furthermore, some studies have not been able to detect emotion recognition deficits in depressive patients. ${ }^{48-50}$ In contrast, Beck et al. ${ }^{51}$ show a better performance of depressed patients. Equally to Beck et al'.s ${ }^{51}$ results, in our study patients with depression did not differ significantly from the healthy 
Table 4. Interaction features $(M \pm S D)$ based on BOEVIAS and Interact

\begin{tabular}{|c|c|c|c|}
\hline Traits & $\begin{array}{l}\text { Patients } \\
(\mathrm{N}=20)\end{array}$ & $\begin{array}{l}\text { Control } \\
(\mathrm{N}=20)\end{array}$ & t-test \\
\hline Positive affect-F & $6.1(4.9)$ & $11.5(5.0)$ & $\mathrm{p}=0.001$ \\
\hline Positive affect-D & $22.6 \mathrm{sec}$ & $67.8 \mathrm{sec}$ & $\mathrm{p}<0.001$ \\
\hline Positive affect-P & 7.4 & 22.6 & $\mathrm{p}<0.001$ \\
\hline Neutral affect-F & $7.1(4.9)$ & $12.0(4.7)$ & $\mathrm{p}=0.003$ \\
\hline Neutral affect-D & $280.2 \mathrm{sec}$ & $230.9 \mathrm{sec}$ & $\mathrm{p}<0.001$ \\
\hline Neutral affect-P & 92.5 & 76.4 & $\mathrm{p}<0.001$ \\
\hline Verbalization-pos-F & $18.0(12.3)$ & $26.4(8.1)$ & $\mathrm{p}=0.015$ \\
\hline Verbalization-pos-D & $74.5 \mathrm{sec}$ & $90.4 \mathrm{sec}$ & $\mathrm{p}=0.333$ \\
\hline Verbalization-pos-P & 24.5 & 29.9 & $\mathrm{p}=0.313$ \\
\hline Silence-F & $25.6(15.7)$ & $35.9(11.4)$ & $\mathrm{p}=0.024$ \\
\hline Silence-D & $221.9 \mathrm{sec}$ & $205.0 \mathrm{sec}$ & $\mathrm{p}=0.323$ \\
\hline Silence-P & 73.3 & 67.8 & $\mathrm{p}=0.329$ \\
\hline Gaze at IP.-F & $17.7(14.0)$ & $31.4(17.1)$ & $\mathrm{p}=0.009$ \\
\hline Gaze at IP.-D & $37.1 \mathrm{sec}$ & $72.6 \mathrm{sec}$ & $\mathrm{p}=0.015$ \\
\hline Gaze at IP.-P & 12.2 & 24.0 & $\mathrm{p}=0.014$ \\
\hline Other visual focus-F & $18.5(13.8)$ & $32.4(17.1)$ & $\mathrm{p}=0.008$ \\
\hline Other visual focus-D & $265.9 \mathrm{sec}$ & $228.6 \mathrm{sec}$ & $\mathrm{p}=0.010$ \\
\hline Other visual focus-P & 87.8 & 75.8 & $\mathrm{p}=0.014$ \\
\hline Vocal pos-F & $3.0(3.6)$ & $5.3(4.9)$ & $\mathrm{p}=0.108$ \\
\hline Vocal-pos-D & $2.2 \mathrm{sec}$ & $3.3 \mathrm{sec}$ & $\mathrm{p}=0.294$ \\
\hline Vocal-pos-P & 0.8 & 1.1 & $\mathrm{p}=0.311$ \\
\hline BOEVIAS-A & $7.9(1.5)$ & $8.7(1.6)$ & $\mathrm{p}=0.087$ \\
\hline BOEVIAS-B & $8.7(2.8)$ & $10.5(3.0)$ & $\mathrm{p}=0.057$ \\
\hline BOEVIAS-C & $8.6(2.3)$ & $10.9(3.0)$ & $\mathrm{p}=0.009$ \\
\hline BOEVIAS-synchronous & $6.5(2.4)$ & $7.0(2.2)$ & $\mathrm{p}=0.541$ \\
\hline BOVIAS-IIP & $24.2(7.0)$ & $33.3(6.2)$ & $\mathrm{p}<0.001$ \\
\hline BOVIAS-SID & $48.4(12.3)$ & $66.3(10.5)$ & $\mathrm{p}<0.001$ \\
\hline
\end{tabular}

F, frequency of occurrence of the event; $\mathrm{D}$, duration of event in seconds; P, percentage of events in relation to total duration; pos, positive; Vocal, vocalization; IP, interaction partner; BOVIAS, Bochumer-Erwachsener Videobasiererte Interaktionsanalyse-Scale; A, expression level, B, relationship level; C, control level; IIP, individual interaction profile; SID, sum interaction of dyade; $M$, mean value; SD, standard deviation; sec, second

controls in terms of emotional recognition skills. An explanation for this could be the fact that these patients were being treated. Another possible explanation for the overall diverging findings on emotion recognition in depressed patients is, as aptly formulated by Wolf et al., ${ }^{5}$ the often non-realistic design of most studies. According to Wolf et al. " "remoteness from everyday life results from the isolated investigation of individual emotions with regard to either the exclusive expression, recognition or experience of this emotion" without taking the multiple contextual influencing factors into account. Com- plex, multilevel studies on emotion processing in depressed patients in general and in the context of successful interpersonal interaction specifically are urgently required. ${ }^{3}$ Zwick and Wolkenstein ${ }^{52}$ examined the ability to recognize emotions and the mimic expression of emotions in 42 acutely depressed, 43 remitted patients, and 39 healthy controls. Patients with severe depressive symptoms showed hypomimia (reduced facial expressions) and strong difficulties in the ability to recognize emotions. However, contrary to expectations, there was no correlation between the patient's facial expression and their deficits in emotion recognition, consequently different processes of emotion processing have to be discussed. A good schema of these different processes and according to neurobiological findings in depressive patients can be found in Kupferberg et al. ${ }^{15}$

\section{Findings concerning INTERACT; BOEVIAS}

The abovementioned findings for ERT show the complexity of social interaction and social functioning, which can be achieved through the interaction of various skills and not only the recognition of emotions. In our study, we found that there were no correlations between emotion recognition and the affect and behavioral characteristics of the examined depressed patients recorded by INTERACT in an experimentally generated interaction situation. Depressed patients in this rather noncommittal small-talk situation showed, despite an increased negative anxiety-depressive state, an interaction behavior that was characterized by neutral affectivity, silence, and avoidance of direct eye contact, similar to the healthy subjects. The main difference was that the depressed patients showed shorter interaction-promoting behaviors (e.g., short glances at the interlocutor or short positive-verbal utterances) and they remained significantly longer in interaction-inhibiting states (e.g., glancing into the room). This can be discussed as an indication that in depressive patients, impairments of social interaction behavior are more likely to be seen in connection with depression-associated slowdown or depressive cognitive-motor inhibition (depressive inhibition). This is also supported by the fact that the patient's individual interaction profile (BOEVIAS) showed strong deficits in the areas of concentration, attention, and activity compared to the healthy controls. These findings can be seen as an expression of psychomotor slowdown and disturbance of executive functions, and are in consensus with the literature. ${ }^{53-55}$ Previous studies on kinematic movement analysis of the facial expressions of patients with depression have already shown that patients show significantly lower speed measures in both the voluntary and involuntary facial expression muscles than healthy people, depending on the severity of the depressive symptoms. ${ }^{13,14}$ Troisi and Moles ${ }^{56}$ also found a general reduction in the sense of a depressive inhibition, especially in their non-verbal interaction 
behavior. They examined 68 depressed patients with 72 healthy controls using scales and direct observation of behavior. Teixeira Fiquer's research group was also able to show a reducedinhibited interaction behavior (verbal as well as non-verbal) in patients with depression, which could be improved by treatment with transcranial stimulation (TCS) ${ }^{56,57}$ Interestingly, however, it was shown that the non-verbal behavior (e.g., eye contact, gestures, or shaking the head) of depressed patients changed little after this therapy measure, whereas speaking or the effort to speak increased. ${ }^{58}$ The verbal communication behavior of depressed patients seems to have changed both quantitatively and qualitatively in the sense that more negative content is formulated. ${ }^{59-61}$

\section{General aspects of communication in depression}

Our findings confirm that positive-verbal communication similar to direct eye contact and body language directed towards the interlocutor is essential for successful social interaction. Therefore, it is not surprising that patients with a depressive disorder and associated impairments in these communication channels have greater difficulties in social interaction. ${ }^{15,18,62,63}$ However, it is unclear if this social dysfunction is only a consequence of depression or, as Porcelli et al. ${ }^{22}$ suggest in their survey work, if a trait feature has a more depressive effect. Although this aspect cannot be conclusively clarified at present, our findings allow the conclusion that depressed patients are not generally incapable of social interaction but that they need more time to adapt and react to a new situation. Radke et al. ${ }^{64}$ reached a similar conclusion when they examined 30 depressive patients with 20 healthy controls with regard to a flexible approach-distance behavior. The depressive patients were not only conspicuous for their less dominant behavior but also for their lack of flexibility in their approaching and avoiding tendencies, and also in affective modulation. ${ }^{64}$

\section{Findings concerning psychometric scales}

Our findings on the impairment of psychosocial functioning and increased neuroticism as a predisposing depressive factor are consistent with the extensive literature on this area of research. ${ }^{65-70}$ Elevated TAS alexithymia levels in patients with depressive disorder have frequently been reported and discussed, which suggests that there is a close relationship between this emotion regulation disorder and depression. ${ }^{16,71-74}$ With regard to PANAS measuring negative or positive affectivity, there are existing studies on reliability and validity ${ }^{44,75}$ but there is a lack of evaluations of this scale among depressive patients. ${ }^{76-78}$ A recent study by Podlogar et al. ${ }^{79}$ found that there was a close connection between an increased risk of suicide and the predominance of negative affectivity (recorded by PANAS in more than 600 anxiety-depressive outpatients).

\section{Limitations}

Our investigation has several limitations. The first limiting factor is the small sample size. Furthermore, this is a monocentric study in which depressed patients were examined who were under drug treatment. Consequently, valid representative statements are possible to a limited extent. A further limiting factor is that the instrumental methods (including the experimental conditions) cannot be regarded as a standard in clinical practice, so that generally valid conclusions also appear critical here. In general, statements on the complex phenomena of behavior and emotionality in the context of social interaction derived from a tightly structured experimental framework and automated analyses are limited because they can only reflect a part of the complex human behavioral repertoire and its emotionality. Finally, only two interactive situations (i.e., watching a movieclip together and sitting together without further instructions) were investigated and were analyzed in a rather basic way. A further comparative situation, such as an instructed conversation, had not been conducted so far. In addition, it must be noted that the use of questionnaires (which were mainly designed specifically for this study and were only rated by the investigators) must be viewed critically because they have not yet been sufficiently validated.

In conclusion, within the framework of a semi-structured experimental paradigm, we were able to examine depressive patients in pairs in regard to emotion processing, their social interaction behavior, and its individual dimensions in more detail. We also made a comparison with healthy controls using newer instrumental measurement methods. Impairments of the social interaction behavior of depressive patients in the sense of reduced-inhibited interaction-promoting non-verbal and verbal activity probably seem to be less associated with disorders of basic skills of emotion recognition and they should be considered more in the context of regulatory disorders of one's own emotionality and cognition given that they do not fundamentally prevent but significantly impede a faster adaptation to the situational conditions in depressive patients. This in turn implies specific psychotherapeutic programs for depressive patients, as called for by Weightman et al., ${ }^{18}$ to optimize their social interaction skills.

Further studies focusing on the interactions of the various communication channels, also in the context of cognitive and metacognitive processes, appear to be necessary. In addition, the technical possibilities could be used more effectively and intensively. It seems to be useful to define more homogeneous subtypes of depressive disorders by this method. In the psychiatric-psychotherapeutic field, an instrumental analysis of interaction and behavior could be useful as a basis for differentiated behavioral treatment strategies for a large proportion of mental illnesses, which are often accompanied by im- 
pairments of social skills. In this respect, research activities need to be intensified and technical equipment needs to be established.

\section{Availability of Data and Material}

The datasets generated or analyzed during the study are available from the corresponding author on reasonable request.

\section{Conflicts of Interest}

Georg Juckel, a contributing editor of the Psychiatry Investigation, was not involved in the editorial evaluation or decision to publish this article. All remaining authors have declared no conflicts of interest.

\section{Author Contributions}

Conceptualization: Georg Juckel, Paraskevi Mavrogiorgou. Data curation: Erhan Akinici, Burhan Akinci, Cora Stiller, Max-Oskar Wieser. Formal analysis: Vera Flasbeck, Simon Vanscheidt, Shirin Diop, Paraskevi Mavrogiorgou. Investigation: Erhan Akinci, Burhan Akinci, Cora Stiller, Max-Oskar Wieser. Project administration: Georg Juckel, Paraskevi Mavrogiorgou. Writingoriginal draft: Erhan Akinic, Paraskevi Mavrogiorgou. Writing-review \& editing: Georg Juckel, Paraskevi Mavrogiorgou.

\section{ORCID iDs}

Erhan Akinci

Max-Oskar Wieser

Simon Vanscheidt

Shirin Diop

Vera Flasbeck

Burhan Akinci

Cora Stiller

Georg Juckel

Paraskevi Mavrogiorgou

https://orcid.org/0000-0002-8632-8298 https://orcid.org/0000-0003-0649-442X https://orcid.org/0000-0001-9693-2256 https://orcid.org/0000-0001-6683-4698 https://orcid.org/0000-0001-6405-4567 https://orcid.org/0000-0002-4745-7994 https://orcid.org/0000-0001-8986-4128 https://orcid.org/0000-0001-9860-9620 https://orcid.org/0000-0002-9138-0445

\section{Funding Statement}

None

\section{REFERENCES}

1. Alharbi SAH, Button K, Zhang L, O'Shea KJ, Fasolt V, Lee AJ, et al. Are affective factors related to individual differences in facial expression recognition? R Soc Open Sci 2020;7:190699.

2. Bourke C, Douglas K, Porter R. Processing of facial emotion expression in major depression: a review. Aust N Z J Psychiatry 2010;44:681-696.

3. Grabowski K, Rynkiewicz A, Lassalle A, Baron-Cohen S, Schuller B, Cummins N, et al. Emotional expression in psychiatric conditions: new technology for clinicians. Psychiatry Clin Neurosci 2019;73:50-62.

4. Kret ME, Ploeger A. Emotion processing deficits: a liability spectrum providing insight into comorbidity of mental disorders. Neurosci Biobehav Rev 2015;52:153-171.

5. Wolf K, Maß R, Lambert M, Wiedemann K, Naber D. Expression, identification and experience of emotions in mental diseases. An overview. Nervenarzt 2014;85:226-235.

6. Ekman P, Friesen WV, O'Sullivan M. Smiles when lying. J Pers Soc Psychol 1988;54:414-420.

7. Ekman P, Davidson RJ, Friesen WV. The Duchenne smile: emotional expression and brain physiology. II. J Pers Soc Psychol 1990;58:342-353.

8. Juckel G. Facial expression and emotions as emplified by depressed patients. Psychoneuro 2005a;31:379-384.

9. Juckel G, Mergl R, Hegerl U. Kinematic movement analyses and their application in psychiatry. Psychiatr Prax 2005b;32:S31-S37.

10. Juckel G, Mergl R, Präßl A, Mavrogiorgou P, Witthaus H, Möller HJ, et al. Kinematic analysis of facial behavior in patients with schizophrenia under emotional stimulation by films with "Mr. Bean". Eur Arch Psy- chiatry Clin Neurosci 2008a;258:186-191.

11. Juckel G, Mergl R, Brüne M, Villeneuve I, Frodl T, Schmitt G, et al. Is evaluation of humorous stimuli associated with frontal cortex morphology? A pilot study using facial micro-movement analysis and MRI. Cortex 2011;47:569-574.

12. Juckel G, Heinisch C, Welpinghus A, Brüne M. Understanding another person's emotions - an interdisciplinary research approach. Front Psychiatry 2018;9:414.

13. Mergl R, Mavrogiorgou P, Hegerl U, Juckel G. Kinematical analysis of emotionally induced facial expressions: a novel tool to investigate hypomimia in patients suffering from depression. J Neurol Neurosurg Psychiatry 2005;76:138-140.

14. Mergl R, Vogel M, Prässl A, Graf B, Karner M, Mavrogiorgou P, et al. Facial expressions and personality: a kinematical investigation during an emotion induction experiment. Neuropsychobiology 2006;54:114119.

15. Kupferberg A, Bicks L, Hasler G. Social functioning in major depressive disorder. Neurosci Biobehav Rev 2016;69:313-332.

16. Banzhaf C, Hoffmann F, Kanske P, Fan Y, Walter H, Spengler S, et al. Interacting and dissociable effects of alexithymia and depression on empathy. Psychiatry Res 2018;270:631-638.

17. Sarkheil P, Kilian-Hütten N, Mickartz K, Vornholt T, Mathiak K. Variation of temporal order reveals deficits in categorisation of facial expressions in patients afflicted with depression. Cogn Neuropsychiatry 2018; 23:154-164.

18. Weightman MJ, Knight MJ, Baune BT. A systematic review of the impact of social cognitive deficits on psychosocial functioning in major depressive disorder and opportunities for therapeutic intervention. Psychiatry Res 2019;274:195-212.

19. Zhang Q, Li X, Wang K, Zhou X, Dong Y, Zhang L, et al. Dullto social acceptance rather than sensitivity to social ostracism in interpersonal interaction for depression: behavioral and electrophysiological evidence from cyberball tasks. Front Hum Neurosci 2017;11:162.

20. Conejero I, Jaussent I, Cazals A, Thouvenot E, Mura T, Le Bars E, et al. Association between baseline pro-inflammatory cytokines and brain activation during social exclusion in patients with vulnerability to suicide and depressive disorder. Psychoneuroendocrinology 2019;99:236242.

21. Kraines MA, Kelberer LJA, Wells TT. Rejection sensitivity, interpersonal rejection, and attention for emotional facial expressions. J Behav Ther Exp Psychiatry 2018;59:31-39.

22. Porcelli S, van der Wee N, van der Werff S, Aghajani M, Glennon JC, van Heukelum S, et al. Social brain, social dysfunction and social withdrawal. Neurosci Biobehav Rev 2019;97:10-33.

23. Mangold P. Softwareunterstützte Audio-/Videoanalyse und Multimodale Datenauswertung in Beobachtungsstudien. In: Bosenick T, Hassenzahl M, Müller-Prove M, Peissner M, Editors. Stuttgart: Usability Professionals, 2006, p.109-111.

24. Braarud HC, Skotheim S, Hoie K, Markhus MW, Kjellevold M, Graff IE, et al. Affective facial expression in sub-clinically depressed and nondepressed mothers during contingent and non-contingent face-to-face interactions with their infants. Infant Behav Dev 2017;48(Pt B):98-104.

25. Chung FF, Wan GH, Kuo SC, Lin KC, Liu HE. Mother-infant interaction quality and sense of parenting competence at six months postpartum for first-time mothers in Taiwan: a multiple time series design. BMC Pregnancy Childbirth 2018;18:365.

26. Reck C. Postpartal depression: possible effects on early mother-child interaction and psychotherapeutical treatment approach. Prax Kinderpsychol Kinderpsychiatr 2007;56:234-244.

27. Reck C, Backenstraß M, Möhler E, Hunt A, Resch F, Mundt C. Motherchild interaction and postpartum depression. Psychother 2001;6:171186.

28. Reck C, Weiss R, Fuchs T, Möhler E, Downing G, Mundt C. Psychotherapy for postpartum depression with a focus on mother-infant interaction. Nervenarzt 2004;75:1068-1073. 
29. Guy W. National Institute of Mental Health: 12-CGI. Clinical Global Impressions. In: Guy W, Bonato RR, Editors. Manual for the ECDEU Assessment Battery. Rev. Ed. Maryland: Chevy Chase, 1970, p.12-112.6.2.

30. Juckel G, Schaub D, Fuchs N, Naumann U, Uhl I, Witthaus H, et al. Validation of the Personal and Social Performance (PSP) Scale in a German sample of acutely ill patients with schizophrenia. Schizophr Res 2008b; 104:287-293.

31. Morosini PL, Magliano L, Brambilla L, Ugolini S, Pioli R. Development, reliability and acceptability of a new version of the DSM-IV Social and Occupational Functioning Assessment Scale (SOFAS) to assess routine social functioning. Acta Psychiatr Scand 2000;101:323-329.

32. Beck AR, Ward M, Mendelson M, Mock J, Erbaugh J. An inventory for measuring depression. Arch Gen Psychiatry 1961;4:561-571.

33. Hautzinger M, Keller F, Kühner C. BDI II. Beck Depressions-Inventory. Revision. Frankfurt: Pearson; 2006.

34. Hamilton M. Development of a rating scale for primary depressive illness. Br J Soc Clin Psychol 1967;6:278-296.

35. Laux L, Glanzmann P, Schaffner P, Spielberger CD. The State-TraitAnxiety-Inventory. Weinheim: Beltz Test GmbH; 1981.

36. Spielberger CD, Gorsuch RL, Lushene RE. State-Trait-Anxiety-Inventory. Palo Alto: Consulting Psychologists Press; 1970.

37. Borkenau P, Ostendorf F. NEO-FFI: NEO Five-Factor-Inventory by Costa and McCrae. Manual (2nd Ed). Göttingen: Hogrefe; 2008.

38. Bagby RM, Taylor GJ, Parker JD. The twenty-item Toronto Alexithymia Scale-II. Convergent, discriminant, and concurrent validity. J Psychosom Res 1994;38:33-40.

39. Parker JDA, Taylor GJ, Bagby RM. The 20-item Toronto Alexithymia Scale-III. Reliability and factorial validity in a community population. J Psychosom Res 2003;55:269-275.

40. Taylor GJ, Bagby RM. New trends in alexithymia research. Psychother Psychosom 2004;73:68-77.

41. Davis M. Measuring individual differences in empathy: evidence for a multidimensional approach. J Pers Soc Psychol 1983;44:113-126.

42. Paulus C. Der Saarbrücker Persönlichkeitsfragebogen SPF (IRI) zur Messung von Empathie. Available at: http://psydok.sulb.uni-saarland. de/volltexte/2009/2363. Accessed Apr 9, 2020.

43. Paulus C. Ist die Bildung eines Empathiescores in der deutschen Fassung des IRI sinnvoll? Available at: http://psydok.sulb.uni-saarland.de/ volltexte/2012/4489. Accessed Apr 9, 2020.

44. Breyer B, Bluemke M. German Version of the Positive and Negative Affect Schedule PANAS (Gesis Panel). Doi: 10.6102/zis242.

45. Lehrl S. The multiple choice vocabulary-test. An intelligence test for medical practice. Neurol Psychiatr 1976;7:488-491.

46. Ekman P, Friesen WV. Unmasking in Face. Englewood Cliffs, NY: Prentice Hall; 1975.

47. Dalili MN, Penton-Voak IS, Harmer CJ, Munafo MR. Meta-analysis of emotion recognition deficits in major depressive disorder. Psychol Med 2015;45:1135-1144.

48. Liedtke C, Kohl W, Kret ME, Koelkebeck K. Emotion recognition from faces with in-and out group features in patients with depression. J Affect Disord 2018;227:817-823.

49. Maniglio R, Gusciglio F, Lofrese V, Belvederri Murri M, Tamburello A, Innamorati M. Biased processing of neutral facial expressions is associated with depressive symptoms and suicide ideation in individuals at risk for major depression due to affective temperaments. Compr Psychiatry 2014;55:518-525.

50. Van Vleet T, Stark-Inbar A, Merzenich MM, Jordan JT, Wallace DL, Lee $\mathrm{MB}$, et al. Biases in processing of mood-congruent facial expressions in depression. Psychiatry Res 2019;275:143-148.

51. Beck T, Mitmansgruber H, Kumnig M, Schüßler G. Depressive have the better view-the influence of mood on the recognition of emotional expression. Z Psychosom Med Psychother 2013;59:247-253.

52. Zwick JC, Wolkenstein L. Facial emotion recognition, theory of mind and the role of facial mimicry in depression. J Affect Disord 2017;210:
90-99.

53. Bayliss AP, Tipper SP, Wakeley J, Cowen PJ, Rogers RD. Vulnerability to depression is associated with a failure to acquire implicit social appraisals. Cogn Emot 2017;31:825-833.

54. LeMoult J, Gotlib IH. Depression: a cognitive perspective. Clin Psychol Rev 2019;69:51-66.

55. Vasic N, Wolf RC, Walter H. Exekutive Funktionen bei depressiven Patienten. [Executive functions in patients with depression. The role of prefrontal activation.] Nervenarzt 2007;78:628-640.

56. Troisi A, Moles A. Gender differences in depression: an ethological study of nonverbal behavior during interviews. J Psychiatr Res 1999;33:243250.

57. Teixeira Fiquer J, Boggio PS, Gorenstein C. Talking bodies: nonverbal behavior in the assessment of depression severity. J Affect Disord 2013; 150:1114-1119.

58. Teixeira Fiquer J, Moreno RA, Canales JZ, Cavalcanti A, Gorenstein C. Is nonverbal behavior in patients and interviewers relevant to the assessment of depression and its recovery? A study with Dutch and Brazilian patients. Psychiatry Res 2017;250:59-64.

59. Backes H, Dietsche B, Nagels A, Stratmann M, Konrad C, Kircher T, et al. Increased neural activity during overt and continuous semantic verbal fluency in major depression: mainly a failure to deactivate. Eur Arch Psychiatry Clin Neurosci 2014;264:631-645.

60. Cruz M, Roter D, Flaum CR, Wieland M, Cooper LA, Larson S, et al. Psychiatrist-patient verbal and nonverbal communications during splittreatment appointments. Psychiatr Serv 2011;62:1361-1368.

61. Rehman US, Ginting J, Karimiha G, Goodnight JA. Revisiting the relationship between depressive symptoms and marital communication using an experimental paradigm: the moderating effect of acute sad mood. Behav Res Ther 2010;48:97-105.

62. Girard JM, Cohn JF, Mahoor MH, Mavadati S, Rosenwald DP. Social risk and depression: evidence from manual and automatic facial expression analysis. Proc Int Conf Autom Face Gesture Recognit 2013:1-8.

63. Loi F, Vaidya JG, Paradiso S. Recognition of emotion from body language among patients with unipolar depression. Psychiatry Res 2013;209:4049.

64. Radke S, Güths F, Ande JA, Müller BW, de Bruijn ERA. In action or inaction? Social approach-avoidance tendencies in major depression. Psychiatry Res 2014;219:513-517.

65. Judd LL, Akiskal HS, Zeller PJ, Paulus M, Leon AC, Maser JD, et al. Psychosocial disability during the long-term course of unipolar major depressive disorder. Arch Gen Psychiatry 2000;57:375-380.

66. Judd LL, Schettler PJ, Rush AJ, Coryell WH, Fiedorowicz JG, Solomon DA. A new empirical definition of major depressive episode recovery and its positive impact on future course of illness. J Clin Psychiatry 2016; 77:1065-1073.

67. Li JJ, Hilton EC, Lu Q, Hong J, Greenberg JS, Mailick MR. Validating psychosocial pathways of risk between neuroticism and late life depression using a polygenic score approach. J Abnorm Psychol 2019;128:200211.

68. Nikolic S, Mladenovic IP, Vucovic O, Barisic J, Svrakic D, Milovanovic $\mathrm{S}$. Individual and gender differences in personality influence the diagnosis of major depressive disorder. Psychiatr Danub 2020;32:97-104.

69. Struijis SY, Lamers F, Spinhoven P, van der Does W, Penninx BWJ. The predictive specifity of psychological vulnerability markers for the course of affective disorders. J Psychiatr Res 2018;103:10-17.

70. Van Sprang ED, Maciejewski DF, Milaneschi Y, Elzinga BM, Beekman ATF, Hartman CA, et al. Familial risk for depressive and anxiety disorders: associations with genetic, clinical, and psychosocial vulnerabilities. Psychol Med 2020;6:1-11.

71. Bressi C, Fronza S, Minacapelli E, Nocito EP, Dipasquale E, Magri L, et al. Short-term psychodynamic psychotherapy with mentalization-based techniques in major depressive disorder patients: relationship among alexithymia, reflective functioning, and outcome variables - a pilot study. Psychol Psychother 2017;90:299-313. 
72. Li S, Zhang B, Guo Y, Zhang J. The association between alexithymia as assessed by the 20 -item Toronto- Alexeithymia-Scale and depression: a meta-analysis. Psychiatry Res 2015;227:1-9.

73. Serafini G, De Berardis D, Valchera A, Canepa G, Geoffroy PA, Pompili $\mathrm{M}$, et al. Alexithymia as a possible specifier of adverse outcomes: clinical correlates in euthymic unipolar individuals. J Affect Disord 2020; 263:428-436.

74. Suslow T, Kugel H, Rufer M, Redlich R, Dohm K, Grotegerd D, et al. Alexithymia is associated with attenuated automatic brain response to facial emotion in clinical depression. Prog Neuropsychopharmacol Biol Psychiatry 2016;65:194-200.

75. Diaz-Gracia A, Gonzalez-Robles A, Mor S, Mira A, Quero S, GarciaPalacios A, et al. Positive and Negative Affect Schedule (PANAS): psychometric properties of the online Spanish version in a clinical sample with emotional disorders. BMC Psychiatry 2020;20:56.
76. Aldinger M, Stopsack M, Barnow S, Rambau S, Spitzer C, Schnell K, et al. The association between depressive symptoms and emotion recognition is moderated by emotion regulation. Psychiatry Res 2013;205:5966.

77. Langvik E, Hjemdal O, Nordah HM. Personality traits, gender differences and symptoms of anhedonia: what does the Hospital Anxiety and Depressive Scale (HADS) measure in nonclinical settings. Scand J Psychol 2016;57:144-151.

78. Remmers C, Topolinski S, Dietrich DE, Michalak J. Impaired intuition in patients with depressive disorder. Br J Clin Psychol 2015;54:200-213.

79. Podlogar MC, Rogers ML, Stanley ICH, Hom MA, Chiurliza B, Joiner TE. Anxiety, depression, and the suicidal spectrum: a latent class analysis of overlapping and distinctive features. Cogn Emot 2018;32:14641477. 